\title{
Brief Novel Visual Experience Fundamentally Changes Synaptic Plasticity in the Mouse Visual Cortex
}

\author{
(DShuo Li, ${ }^{1 \star}$ Laijian Wang, ${ }^{1 \star}$ Xiaoxiu Tie, ${ }^{1,2}$ Kazuhiro Sohya, ${ }^{3}{ }^{\circledR X i a n ~ L i n, ~}{ }^{1}$ Alfredo Kirkwood, ${ }^{2}$ and $\odot$ Bin Jiang ${ }^{1}$ \\ ${ }^{1}$ Guangdong Province Key Laboratory of Brain Function and Disease, Faculty of Forensic Medicine, Zhongshan School of Medicine, Sun Yat-sen University, \\ Guangzhou, 510080 China, ${ }^{2}$ Mind/Brain Institute, Johns Hopkins University, Baltimore, Maryland 21218, and ${ }^{3}$ Department of Mental Disorder Research, \\ National Institute of Neuroscience, National Center of Neurology and Psychiatry, Kodaira, Tokyo, 187-8502, Japan
}

LTP has been known to be a mechanism by which experience modifies synaptic responses in the neocortex. Visual deprivation in the form of dark exposure or dark rearing from birth enhances NMDAR-dependent LTP in layer 2/3 of visual cortex, a process often termed metaplasticity, which may involve changes in NMDAR subunit composition and function. However, the effects of reexposure to light after dark rearing from birth on LTP induction have not been explored. Here, we showed that the light exposure after dark rearing revealed a novel NMDAR independent form of LTP in the layer $2 / 3$ pyramidal cells in visual cortex of mice of both sexes, which is dependent on mGluR5 activation and is associated with intracellular $\mathrm{Ca}^{2+}$ rise, CaMKII activity, PKC activity, and intact protein synthesis. Moreover, the capacity to induce mGluR-dependent LTP is transient: it only occurs when mice of both sexes reared in the dark from birth are exposed to light for 10-12 h, and it does not occur in vision-experienced, male mice, even after prolonged exposure to dark. Thus, the mGluR5-LTP unmasked by short visual experience can only be observed after dark rearing but not after dark exposure. These results suggested that, as in hippocampus, in layer $2 / 3$ of visual cortex, there is coexistence of two distinct activity-dependent systems of synaptic plasticity, NMDAR-LTP, and mGluR5-LTP. The mGluR5-LTP unmasked by short visual experience may play a critical role in the faster establishment of normal receptive field properties.

Key words: dark rearing; light exposure; postnatal development; synaptic plasticity; visual cortex

Significance Statement

LTP has been known to be a mechanism by which experience modifies synaptic responses in the neocortex. Visual deprivation in the form of dark exposure or dark rearing from birth enhances NMDAR-dependent LTP in layer $2 / 3$ of visual cortex, a process often termed metaplasticity. NMDAR-dependent form of LTP in visual cortex has been well characterized. Here, we report that an NMDARindependent form of LTP can be promoted by novel visual experience on dark-reared mice, characterized as dependent on intracellular $\mathrm{Ca}^{2+}$ rise, PKC activity, and intact protein synthesis and also requires the activation of mGluR5. These findings suggest that, in layer $2 / 3$ of visual cortex, as in hippocampus, there is coexistence of two distinct activity-dependent systems of synaptic plasticity.

\section{Introduction}

LTP and LTD are the most comprehensive models of the synaptic modifications underlying experience-dependent cortical plastic-

Received Feb. 4, 2017; revised Aug. 4, 2017; accepted Aug. 11, 2017.

Author contributions: A.K. and B.J. designed research; S.L. and L.W. performed research; X.T., K.S., and X.L. contributed unpublished reagents/analytic tools; S.L., L.W., K.S., A.K., and B.J. analyzed data; A.K. and B.J. wrote the paper.

This study was supported in part by National Natural Science Foundation of China Natural Grant 31171056 to B.J. and National Institutes of Health/National Institute on Aging Grant R01AG034606 to A.K.

The authors declare no competing financial interests.

*S.L. and L.W. contributed equally to this work.

Correspondence should be addressed to either of the following: Dr. Bin Jiang, Guangdong Province Key Laboratory of Brain Function and Disease, Faculty of Forensic Medicine, Zhongshan School of Medicine, Sun Yat-sen University, 74 Zhongshan Road 2, Guangzhou, 510080 China, E-mail: jiangb3@mail.sysu.edu.cn; or Dr. Alfredo Kirkwood, Mind Brain Institute, Johns Hopkins University, 338 Krieger Hall, 3400 N. Charles Street, Baltimore, MD 21218, E-mail: kirkwood@jhu.edu. ity (Tsumoto, 1992; Bear, 2003). In visual cortex, LTP and LTD have been demonstrated across all cortical layers; their mechanisms, the rules of induction, and consequences have been primarily studied in layer 2/3 pyramidal cells (Komatsu et al., 1981; Artola and Singer, 1987; Kimura et al., 1989; Kirkwood et al., 1994; Heynen and Bear, 2001; Wang and Daw, 2003; Daw et al., 2004; Rao and Daw, 2004; Jiang et al., 2007; Cooke and Bear, 2010). These studies established that, in layer $2 / 3$, the induction of LTP and LTD is Hebbian and depends on NMDAR activations (Bear et al., 1992; Kirkwood and Bear, 1994) and the history of visual experience. Thus, visual deprivation in the form of dark exposure (DE) or dark rearing (DR) from birth enhances NMDAR-dependent LTP in layer 2/3 of visual cortex (Kirkwood 
and Bear, 1994; Kirkwood et al., 1995, 1996; Guo et al., 2012), a process often termed metaplasticity (Abraham and Bear, 1996), through a mechanism that involves changes in the NMDAR subunit composition and function during metaplasticity (Quinlan et al., 1999a, b; Philpot et al., 2001). Notably, the consequence for plasticity of the opposite process, reexposure to light, has not been fully explored. The scarcity of data prompted us to examine the changes in plasticity evoked by exposing light to mice that have been reared in the dark since birth. We found that this simple manipulation unmasks an mGluR5-dependent LTP in the layer $2 / 3$ of visual cortex. This new type of LTP depended on intracellular $\mathrm{Ca}^{2+}$ rise, CaMKII activity, PKC activity, and intact protein synthesis. Thus, we demonstrated that, as in hippocampus (Lüscher and Huber, 2010; Wang et al., 2016), in layer 2/3 of visual cortex, there is coexistence of two distinct activitydependent systems of synaptic plasticity. The mGluR5-LTP unmasked by short visual experience may play a critical role in the faster establishment of normal receptive field properties.

\section{Materials and Methods}

Animals. Male and female C57BL/6J mice at P18-P26 and male C57BL/6J mice older than P35 were used. All subjects were fed ad libitum. Control normally reared (NR) mice were raised on a 12:12 light/dark cycle. For $\mathrm{DR}$, mice were kept in a darkroom; feeding and cage cleaning was performed wearing an infrared visor. To monitor the effectiveness of the light seal, photographic film was exposed in the darkroom for several days before use. DE or light exposure (LE) was performed by placing subjects in a darkroom or on the normal light/dark cycle, respectively. All animal experimental procedures were approved by the Animal Care and Use Committees of Sun Yat-sen University and John Hopkins University and were performed in accordance with the guidelines of the National Institutes of Health on animal care and the ethical guidelines. The minimum number of animals was used in each experiment.

Visual cortical slices. Coronal slices ( $300 \mu \mathrm{m}$ thick) containing V1 were prepared as described previously (Jiang et al., 2010a; Sun et al., 2015) using a tissue slicer (Vibratome 3000; Vibratome) in ice-cold dissection buffer containing the following (in $\mathrm{mM}$ ): 212.7 sucrose, $3 \mathrm{KCl}, 1.25$ $\mathrm{NaH}_{2} \mathrm{PO}_{4}, 3 \mathrm{MgCl}_{2}, 1 \mathrm{CaCl}_{2}, 26 \mathrm{NaHCO}_{3}$, and 10 dextrose, bubbled with $95 \% \mathrm{O}_{2} / 5 \% \mathrm{CO}_{2}$. They were immediately transferred to ACSF at $35^{\circ} \mathrm{C}$ for 30 min before recordings. ACSF was similar to the dissection buffer, except that sucrose was replaced with $124 \mathrm{~mm} \mathrm{NaCl}\left(\mathrm{MgCl}_{2}\right.$ at $1 \mathrm{~mm}$ and $\mathrm{CaCl}_{2}$ at $2 \mathrm{~mm}$ ). All recordings were performed at $31^{\circ} \mathrm{C}$. Pyramidal cells in layer $2 / 3$ were identified visually under infrared differential interference contrast optics on the basis of their pyramidal somata and prominent apical dendrites, as described previously (Jiang et al., 2007; Sun et al., 2015).

Evoked postsynaptic current recordings. Evoked EPSCs (eEPSCs) were recorded from pyramidal cells in layer $2 / 3$ by whole-cell voltage-clamp method. A concentric bipolar stimulating electrode with a tip diameter of $125 \mu \mathrm{m}$ (FHC) was placed in layer 4 to evoke excitatory responses onto pyramidal cells in layer $2 / 3$. The distance between stimulating and recording electrode was kept at $80-120 \mu \mathrm{m}$. Patch pipettes $(2-4 \mathrm{M} \Omega$ ) were filled with the internal solution consisting of the following (in $\mathrm{mM}$ ): 120 Cs-methylsulfonate, 10 HEPES, 10 Na-phosphocreatine, 5 lidocaine $N$-ethyl bromide (QX-314), 4 ATP, 0.5 GTP, pH 7.2-7.3; the osmolarity of the solution was $270-285 \mathrm{mOsm}$. Only cells with series resistance $<20$ $\mathrm{M} \Omega$ and input resistance $>100 \mathrm{~m} \Omega$ were studied. On average, the cells from NR, DR, and DR LE mice had similar input resistances (NR: $223.88 \pm 9.6 \mathrm{M} \Omega, n=46$; DR: $220.1 \pm 12.6 \mathrm{M} \Omega, n=32$; $10-12$ h LE: $230.95 \pm 11.1 \mathrm{M} \Omega, n=41$; Kruskal-Wallis: 0.5546 ; $p=0.7578$ ). Cells were excluded if input resistance changed $>15 \%$ or series resistance changed $>10 \%$ over the experiment. Data were filtered at $3 \mathrm{kHz}$ and digitized at $10 \mathrm{kHz}$ using Igor Pro (WaveMetrics). To induce LTP, pairing protocol was applied. In brief, conditioning stimulation consisted of 360 pulses at $2 \mathrm{~Hz}$ paired with continuous postsynaptic depolarization $(180 \mathrm{~s})$ to $0 \mathrm{mV}$. To suppress excessive polysynaptic activity, picrotoxin $(50 \mu \mathrm{M})$ was added in the recording bath, and the concentration of diva- lent cations was elevated to $4 \mathrm{~mm} \mathrm{Ca}^{2+}$ and $4 \mathrm{mM} \mathrm{Mg}^{2+}$ to reduce recruitment of polysynaptic responses. A test pulse was delivered at 0.05 $\mathrm{Hz}$ to monitor baseline amplitude for $10 \mathrm{~min}$ before and for 25-35 min following paired stimulation.

NMDAR-EPSCs were recorded by holding the cells at $40 \mathrm{mV}$ in the similar solution in which LTP was induced but CNQX $(20 \mu \mathrm{m})$ was added. To evaluate the decay kinetics of the NMDAR-EPSCs, 30-50 traces were first averaged and normalized. Then the decay was fitted with two exponentials, one fast and one slow, using Igor. As a measure of the decay, we calculated a weighted time constant $\left(\tau_{\mathrm{w}}\right)$ according to the following equation as described previously (Rumbaugh and Vicini, 1999; Philpot et al., 2001): $\tau_{\mathrm{w}}=\tau_{\mathrm{f}}\left[I_{\mathrm{f}} /\left(I_{\mathrm{f}}+I_{\mathrm{s}}\right)\right]+\tau_{\mathrm{s}}\left[I_{\mathrm{s}} /\left(I_{\mathrm{f}}+I_{\mathrm{s}}\right)\right]$ where $\tau_{\mathrm{f}}$ and $\tau_{\mathrm{s}}$ are the time constants for the fast and slow components and $\mathrm{I}_{\mathrm{f}}$ and $\mathrm{I}_{\mathrm{s}}$ are their respective amplitudes.

Drug solutions. Drugs were applied either through the perfusion medium or the internal solution of recording pipettes. When drugs were applied through the internal solution, control recordings using the internal solution alone or the vehicle alone were made in slices from the same mice as used for test recordings. In case of the bath application, interleaved control recordings were made in slices without drug from the same animals. We used the following drugs as selective antagonists for respective type of glutamate receptors: DL-APV (Sigma) at $100 \mu \mathrm{M}$ for NMDAR, 2-methyl-6-(phenylethynyl) pyridine hydrochloride (MPEP; Tocris Bioscience) at $10 \mu \mathrm{M}$ for mGluR5, $(s)-(+)$ - $\alpha$-amino-4-carboxy2-methylbenzeneacetic acid (LY 367385; Tocris Bioscience) at $100 \mu \mathrm{M}$ for mGluR1, and (2S)-2-amino-2-[(1S,2S)-2-carboxycycloprop-1-yl]3-(xanth-9-yl) propanoic acid (LY 341495; Tocris Bioscience) at $20 \mu \mathrm{M}$ for Group II and Group III mGluRs (Kingston et al., 1998; Capogna, 2004). We used $(2 R, 3 S, 4 S)$-2-[(4-methoxyphenyl)methyl]-3,4-pyrrolidinediol 3 -acetate (anisomycin, Tocris Bioscience) at $10 \mu \mathrm{M}$ and 4 -[2-(3,5dimethyl-2-oxo-cyclohexyl)-2-hydroxyethyl]-2,6-piperidinedione (cycloheximide, Tocris Bioscience) at $60 \mu \mathrm{M}$ as selective antagonists for protein synthesis. We applied 3-(1H-indol-3-yl)-4-[1-[2-(1-methyl-2pyrrolidinyl)ethyl]- $1 \mathrm{H}$-indol-3-yl]-1 $H$-pyrrole-2,5-dione (bisindolyl maleimide II, Tocris Bioscience) at $10 \mu \mathrm{M}$ and $[9 S-(9 \alpha, 10 \beta, 11 \beta, 13 \alpha)]$ $N$-(2,3,10,11,12,13-hexahydro-10-methoxy-9-methyl-1-oxo-9,13-epoxy- $1 \mathrm{H}$, $9 H$-diindolo[1,2,3-gh:3',2',1'-lm]pyrrolo[3,4-j][1,7]benzodiazonin-11-yl)- $N$ methylbenzamide (CGP 41251, Tocris Bioscience) at $10 \mu \mathrm{M}$ as selective antagonists for PKC activation. To block protein kinase A (PKA), $20 \mu \mathrm{M}$ PKI 6-22 amide (Merck) was used in the electrode filling solution. To block CaMKII, $20 \mu \mathrm{M}$ autocamptide-2 related inhibitor peptide (AIP) (Sigma) was used in the electrode filling solution (Yasuda et al., 2003; Hardingham et al., 2008).

Statistical analysis. To calculate LTP, the EPSC amplitude was normalized to the mean baseline amplitude during $10 \mathrm{~min}$ baseline. Potentiation was defined as the mean normalized EPSC amplitude 25-35 min after paired stimulation. Statistical significance was assessed with GraphPad Prism using unpaired or paired $t$ tests, or one-way ANOVA followed by the Student-Newman-Keuls post hoc test in the cases normal distribution (Agostino-Pearse Omnibus Test); in the other cases, we used the MannWhitney or the Kruskal-Wallis test. All the data reported in the text and figures represent the mean \pm SEM.

\section{Results}

\section{Novel visual experience unmasks an NMDAR-independent LTP in layer $2 / 3$ of mouse visual cortex}

Previous studies showed that visual deprivation in the form of $\mathrm{DE}$ for several days or DR from birth enhances LTP (Kirkwood et al., 1995, 1996; Philpot et al., 2001, 2003; Jiang et al., 2007; Guo et al., 2012 ) in layer $2 / 3$ of visual cortex, a process often termed metaplasticity (Abraham and Bear, 1996). We examined the effects of reexposure to light after DR from birth. We recorded the EPSCs in layer $2 / 3$ pyramidal cells evoked by layer 4 stimulation to induce LTP; we paired 360 stimulation pulses $(2 \mathrm{~Hz}$ ) with continuous depolarization to $0 \mathrm{mV}$ (for further details, see Materials and Methods). First, we confirmed in cells from NR young mice (P19-P22) that the pairing induces a robust LTP (135.3 $\pm 4.2 \%$ of baseline measured $25-35 \mathrm{~min}$ after pairing; $n=11$ cells, 5 
A

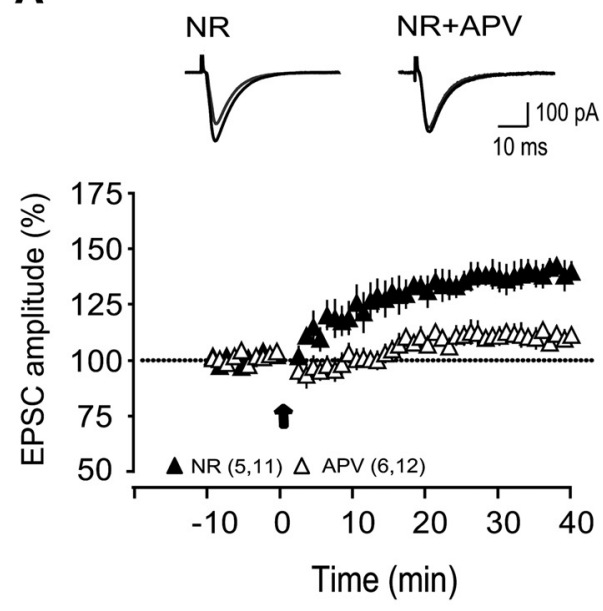

C
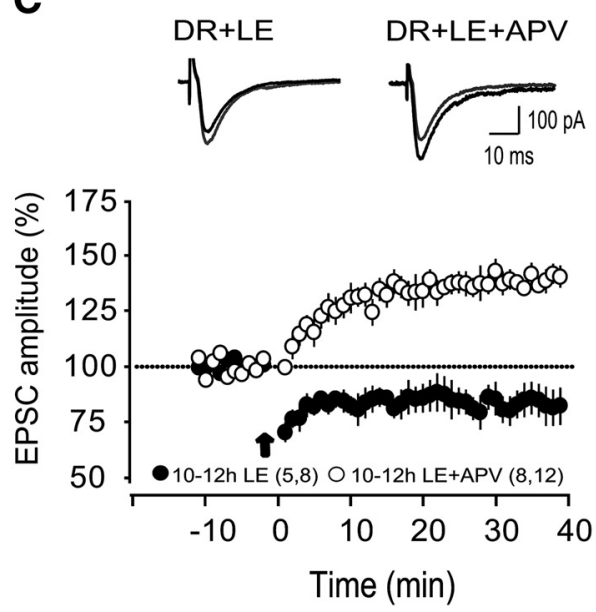

B
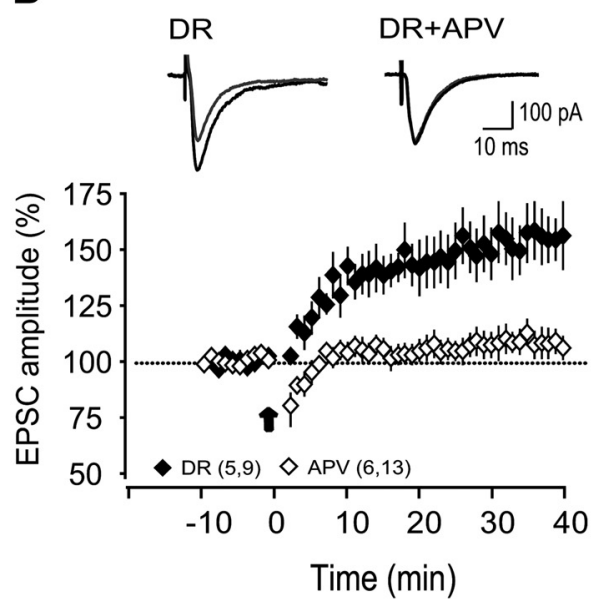

D

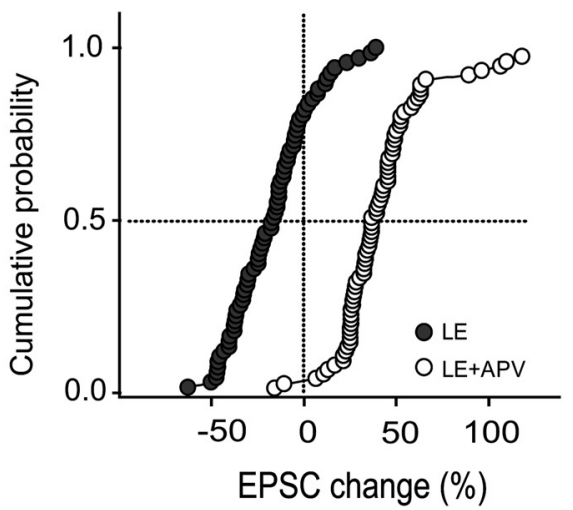

Figure 1. Novel visual experience unmasks a robust NMDAR-independent LTP in layer $2 / 3$ of mouse visual cortex. $A$, Time course of changes in EPSC amplitude after pairing protocol $(0 \mathrm{mV}, 2 \mathrm{~Hz}$, 360 pulses, arrowhead) from normal-reared mice at P19-P21 recorded in ACSF (filled triangles) and in the presence of APV (open triangles). $\boldsymbol{B}$, Time course of changes in EPSC amplitude after pairing protocol ( $0 \mathrm{mV}, 2 \mathrm{~Hz}, 360$ pulses, arrowhead) from dark-reared mice at P19-P21 recorded in ACSF (filled diamonds) and in the presence of APV (open diamonds). $C$, Time course of changes in EPSC amplitude after pairing protocol $(0 \mathrm{mV}, 2 \mathrm{~Hz}, 360$ pulses, arrowhead) from dark-reared mice, which were exposed to light for $10-12 \mathrm{~h}$ recorded in ACSF (filled circles) and in the presence of APV (open circles). $\boldsymbol{A}-\boldsymbol{C}$, The average of 10 consecutive EPSCs recorded before (gray trace) and $30-35 \mathrm{~min}$ after (black trace) pairing. Calibration, Right: $10 \mathrm{~ms}, 100$ pA. D, Cumulative probabilities for LTD and LTP induction in the DR mice briefly exposed to light for 10-12 h without APV (filled circles) and with APV (open circles).

mice; Fig. 1A), which was sensitive to NMDA receptor blockade with $100 \mu \mathrm{M}$ APV $(109.7 \pm 2.5 \%, n=12$ cells, 6 mice; Fig. $1 A$; ACSF vs APV, unpaired $t$ test, $\left.t_{(21)}=4.854, p=0.00028\right)$. We also confirmed that, in cells from mice DR from birth, the same pairing protocol induced an LTP that was much larger than in cells from NR mice (DR: $154.1 \pm 5.1 \%, n=9$ cells, 5 mice; NR: $135.33 \pm 4.3 \%, n=10$ cells, 4 mice; Fig. $1 B$; NR vs DR, unpaired $t$ test, $\left.t_{(17)}=2.62, p=0.018\right)$, and it was blocked by APV $(103.9 \pm$ $4.9 \%, n=13$ cells, 6 mice; Fig. $1 B$; ACSF vs APV, unpaired $t$ test, $\left.t_{(20)}=6.03, p<0.0001\right)$. Next, we studied cells from DR mice briefly exposed to light for 10 or $12 \mathrm{~h}$ (LE). In this case, the pairing protocol induced LTD rather than LTP $(83.3 \pm 5.4 \%, n=8$ cells, 5 mice; paired $t$ test: $t_{(14)}=3.52, p=0.0034$; Fig. $\left.1 C\right)$; and notably, this was reverted to LTP in the presence of APV (APV: $138.7 \pm 5.4 \%, n=12$ cells, 8 mice; Fig. $1 C$ ). These two unexpected types of plasticity detected in the slices from LE were robust. Pairing-induced LTD $>15 \%$ was observed in 36 of 66 cases, and NMDAR-independent LTP $>15 \%$ was observed in 69 of 74 cases (Fig. 1D). These results indicate that visual experience after DR profoundly changes synaptic plasticity: it promotes NMDAR-dependent LTD at the expense of NMDAR-dependent
LTP and reveals an NMDAR-independent form of LTP that is novel in layer $2 / 3$ pyramidal cells.

\section{LE restores the normal NMDAR subunit composition at the synapse}

This study focuses on the NMDAR-independent form of LTP that appears after LE. Nevertheless, it was also of interest to examine whether the drastic alterations in NMDAR-dependent LTP relate to changes in the NMDAR subunit composition. It is well established that the ratio of NR2B/NR2A subunits at the synapse changes during postnatal development in an experiencedependent manner (Quinlan et al., 1999a, b; Philpot et al., 2001), which in turn affects the induction of NMDAR-dependent LTP/ LTD (Philpot et al., 2001; Guo et al., 2012). Therefore, we evaluated the functional fraction of NR2B at the synapse in the three conditions (NR, DR, and LE) by measuring the proportion of the isolated NMDAR response blocked by the NR2B antagonist ifenprodil $(3 \mu \mathrm{M})$ and the changes in the decay constant of the responses. We found that (1) the fraction blocked by infenprodil (Fig. 2A) and the decay constant of the response (Fig. 2B) were larger in DR mice, which is consistent with an increased propor- 
tion of synaptic NR2B; and (2) the brief LE restored the normal values of both measures. In both cases, the statistical significance was confirmed with an ANOVA test followed by a Student-NewmanKeuls test (percentage blockade by infenprodil: $F_{(2,29)}=8.972, p=0.00091$; decay time: $\left.F_{(2,29)}=27.66, p=0.000013\right)$. These results are consistent with a rapid lightinduced restoration of $\mathrm{NR} 2 \mathrm{~A} / 2 \mathrm{~B}$ protein levels reported previously (Quinlan et al., 1999a), and argue against a role of altered NMDAR function in the changes of NMDAR-dependent LTP/LTD after LE.

Activation of mGluR mediates the induction of NMDAR-independent LTP promoted by vision after DR

The NMDAR-independent form of LTP described above is highly reminiscent of an mGluR-dependent form of LTP that is promoted by experience after deprivation in the somatosensory cortex (Clem et al., 2008; Wen et al., 2013). Therefore, we examined whether this form of LTP induced after blockade of NMDA receptor is mGluR-dependent. Cells from DR mice briefly exposed to light for 10 or $12 \mathrm{~h}$ were studied in APV, and several antagonists against mGluRs were tested. MPEP $(10 \mu \mathrm{M})$, an mGluR5 antagonist, completely eliminated LTP (APV+MPEP: $84.4 \pm 6.1 \%$, 25-35 min after pairing, $n=9$ cells, 4 mice; APV only: $138.3 \pm 9.1 \%, n=10$ cells, 4 mice; Fig. $3 A$; unpaired $t$ test: $\left.t_{(17)}=4.43, p=0.0004\right)$. On the other hand, neither LY367385 (100 $\mu \mathrm{M})$, a selective $\mathrm{mGlu}_{1 \mathrm{a}}$ receptor antagonist, nor LY $341495(20 \mu \mathrm{M})$, a selective Type II and III mGluRs antagonist, blocked LTP (APV: $145.2 \pm 8.1 \%, 30 \mathrm{~min}$ after pairing, $n=9$ cells, 5 mice; APV + LY367385: $143.7 \pm 4.2 \%$, $n=7$ cells, 4 mice; APV +LY 341495: $147.8 \pm 6.6 \%, n=8$ cells, 4 mice; Fig. $\left.3 B ; F_{(2,21)}=0.06, p=0.942\right)$. Collectively, these data suggest that, in the mouse visual cortex, novel visual experience unmasks a form of LTP that depends on mGluR5 activation.

In CA1 synapses of the hippocampus, an mGluR-dependent form of LTD can be elicited simply by bath application of the Type I mGluR agonist DHPG (Palmer et al., 1997; Huber et al., 2000). We therefore tested whether bath-applied DHPG (100 $\mu \mathrm{M}, 10 \mathrm{~min}$ ) enables LTP in slices from LE mice. As shown in Figure $3 C$, the agonist elicited a strong potentiation that persists after the removal of the drug, but only in the slices from LE mice, and not in the slices from dark reared (but not exposed) mice (DR + 10-12 h LE: $149.5 \pm 11.2 \%, 20-30$ min after cessation of DHPG, $n=10$ cells, 4 mice; DR: $105.9 \pm 5.1 \%, n=9$ cells, 4 mice; unpaired $t$ test, $\left.t_{(17)}=2.97, p=0.0085\right)$. These LTP-like changes induced by the agonist were blocked by mGluR5 antagonist MPEP (99.1 $\pm 2.3 \%$ 20-30 min after cessation of DHPG, $n=9$ cells, 5 mice; Fig. $3 C$ ). These results suggest that activation of mGluR5 receptors is necessary and sufficient to induce an NMDAR-independent form of LTP in visually exposed mice. We also applied DHPG together with LY367385 because there is the possibility that DHPG activates mGluR1 as well as mGluR5. We found that the additional application of this selective antagonist for mGluR1 did not significantly affect the enhancing action of DHPG $(145.3 \pm 4.5 \%, 20-30 \mathrm{~min}$ after cessation of DHPG, $n=$ 7 cells, 4 mice; data not shown). This suggests that the enhancement of EPSCs by DHPG in the cells from DR mice briefly exposed to light for 10 or $12 \mathrm{~h}$ is mainly induced through its action on mGluR5.

Previous studies indicated that, in other synapses, the induction of mGluR-dependent forms of LTP requires a postsynaptic increase in $\mathrm{Ca}^{2+}$ (Clem et al., 2008). To test whether this is also the case with the LTP enabled by LE, we included the $\mathrm{Ca}^{2+}$ chelator BAPTA $(10 \mathrm{~mm})$ in the recording pipettes. Recordings were initiated 5 min seal breaking to allow BAPTA to spread in the neurons. We found that, in the slices from LE mice, mGluR5dependent LTP was completely eliminated in the BAPTA-loaded cells (APV: $144.1 \pm 9.1 \%, n=7$ cells, 5 mice; APV+BAPTA: $87.1 \pm 3.8 \%, n=9$ cells, 5 mice; Fig. $3 D$; unpaired $t$ test, $t_{(14)}=$ $4.45, p=0.0005)$, supporting the idea that a postsynaptic elevation of $\mathrm{Ca}^{2+}$ is necessary to induce mGluR5-LTP.

\section{Mechanisms of expression of mGluR-LTP promoted by vision} after DR

In CA1 synapses of the hippocampus, the induction of an mGluR-dependent form of LTP requires normal protein transla- 
A

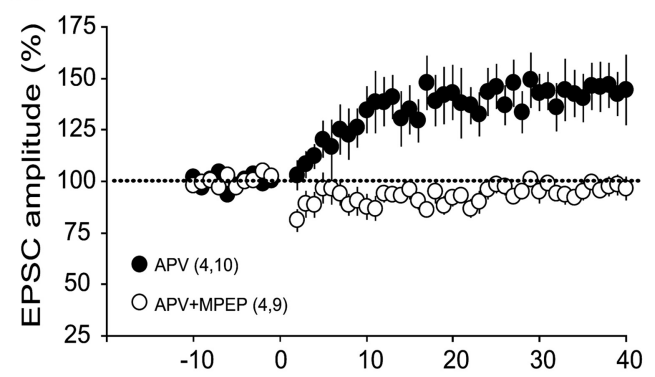

C

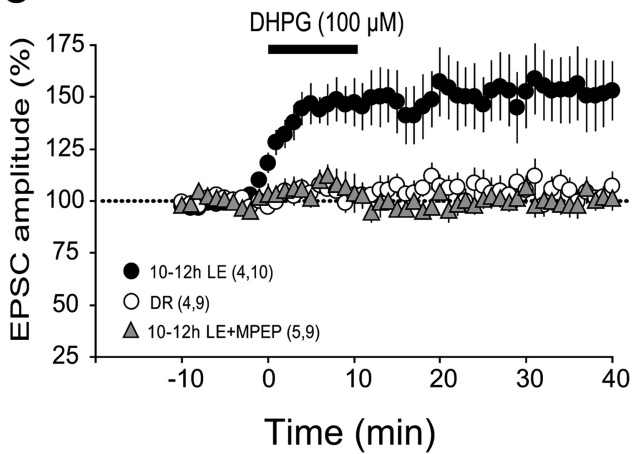

B

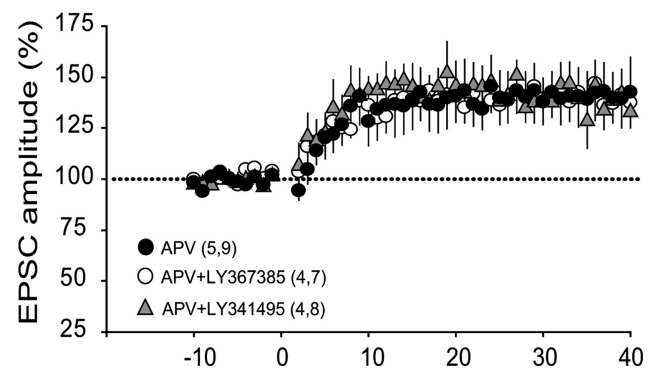

D

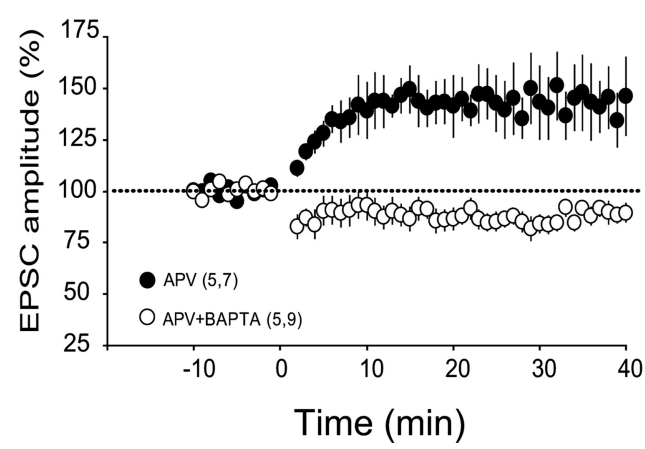

Figure 3. The novel form of LTP is mGluR5-dependent and requires postsynaptic $\mathrm{Ca}^{2+}$ rise. $A$, APV-unmasked LTP after $10-12 \mathrm{~h}$ novel LE from DR mice was completely blocked by mGluR5 antagonist MPEP (filled circles represent APV; open circles represent MPEP). B, APV-unmasked LTP could still be induced at the presence of Group I//III and mGluR1 antagonists (filled triangles represent LY 341495; open circles represent LY367385; filled circles represent APV). C, Group I mGluR agonist DHPG directly induced an mGluR5-dependent potentiation of EPSCs from dark-reared mice after 10-12 h LE (filled circles represent LE; open circles represent DR; filled triangles represent LE + MPEP). D, APV-unmasked LTP required postsynaptic intracellular Ca ${ }^{2+}$ rise (filled circles represent APV; open circles represent BAPTA).

A

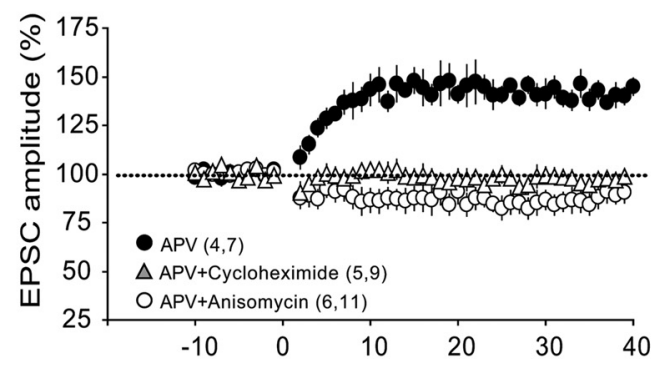

C

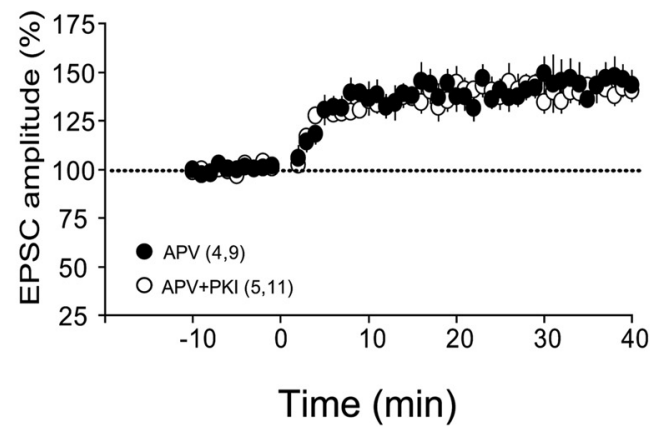

B

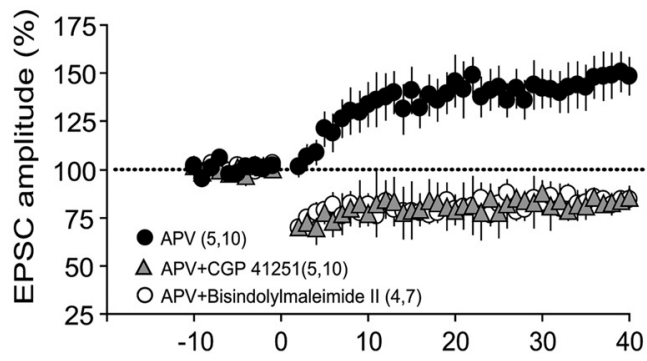

D

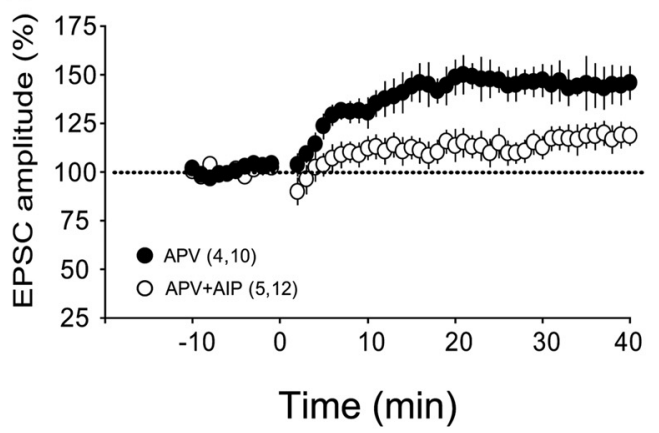

Figure 4. mGluR-LTP promoted by vision after DR depends on PKC activity and intact protein synthesis. A, Protein synthesis inhibitors blocked APV-unmasked LTP (filled triangles represent cycloheximide; open circles represent anisomycin; filled circles represent APV). B, PKC inhibitors blocked APV-unmasked LTP (filled triangles represent CGP 41251; open circles represent bisindolylmaleimide II; filled circles represent APV). C, PKA inhibitor did not block APV-unmasked LTP (filled circles represent APV; open circles represent PKI). D, CaMKII inhibitor blocked APV-unmasked LTP (filled circles represent APV; open circles represent AIP). 
tion (Wang et al., 2016); accordingly, we examined whether mGluR5-LTP in visual cortex promoted by vision also depends on protein translation. Two protein synthesis inhibitors, anisomycin $(10 \mu \mathrm{M})$ and cycloheximide $(60 \mu \mathrm{M})$, were used, respectively. Brain slices were incubated for at least $30 \mathrm{~min}$ before collecting baseline, and the inhibitors were applied throughout the experiment. In the presence of anisomycin or cycloheximide, mGluR5-LTP was completely blocked (APV: $142.7 \pm 5.3 \%, n=$ 7 cells, 4 mice; APV + anisomycin: $87.1 \pm 5.1 \%, n=11$ cells, 6 mice; APV + cycloheximide: $98.31 \pm 2.8 \%, n=9$ cells, 5 mice; Fig. $4 A$; ANOVA test, $\left.F_{(2.24)}=36.01, p=0.00001\right)$. Therefore, similar to mGluR-mediated plasticity in CA1 of hippocampus, mGluR5-LTP in visual cortex requires the intact protein synthesis.

Next, we examined the role of protein kinases in the induction of mGluR-LTP. Of particular interest was PKC, a downstream target of mGluR activity and essential for various form of LTP (D’Angelo et al., 1999; Yamada et al., 2006; Scott et al., 2007). Its role in mGluR-LTP was tested by extracellular application of two types of PKC inhibitors, bisindolylmaleimide II at $10 \mu \mathrm{M}$ and CGP 41251 at $10 \mu \mathrm{M}$, respectively. mGluR5-LTP was blocked by either inhibitor (APV: $141.9 \pm 4.1 \%, n=10$ cells, 5 mice; CGP 41251: $83.3 \pm 3.5 \%, n=10$ cells, 5 mice; bisindolylmaleimide II: $84.7 \pm 6.5 \%, n=7$ cells, 4 mice; Fig. $4 B$; ANOVA test, $\left.F_{(2,24)}=49.53, p<0.0001\right)$, suggesting that PKC is necessary for mGluR5-LTP induction.

It was previously reported that a form of LTP dependent on PKA is unmasked by whisker deprivation in barrel cortex (Hardingham et al., 2008). To examine the role of PKA in visual cortical mGluRLTP, we tested the effects of loading the cells with the inhibitor PKI 6-22 amide (20 $\mu \mathrm{M}$ in the recording pipette). The pairing conditioning induced substantial LTP in both control cells and cells loaded with PKI 6-22 amide (Control: $142.09 \pm$ $6.1 \%, n=9$ cells, 4 mice; PKI: $140.95 \pm$ $3.3 \%, n=11$ cells, 5 mice; unpaired $t$ test, $t_{(18)}=0.1683, p=0.8681$; Fig. $\left.4 C\right)$, suggesting that PKA is not necessary for mGluR5-LTP induction.

There is strong evidence for a mandatory role of CaMKII in LTP induction (Nicoll and Malenka, 1999; Lisman et al., 2002). To examine whether CaMKII activity is required for the mGluR5-LTP, we loaded layer 2/3 pyramidal cells with $20 \mu \mathrm{M}$ AIP. In this case, robust LTP was only elicited in control cells but not in the cells loaded with AIP (Control: $145.33 \pm 7.2 \%, n=10$ cells, 4 mice; AIP: $114.33 \pm 4.3 \%, n=12$ cells, 5 mice; unpaired $t$ test, $t_{(20)}=3.869, p=0.001$; Fig. $4 D$ ), suggesting a role of CaMKII activity in the induction of mGluR5LTP. Together, these results indicate that the induction of mGluR5-LTP in visual cortex promoted by short, novel visual experience depends on activation of PKC and CaMKII, postsynaptic $\mathrm{Ca}^{2+}$ rise, and intact protein synthesis.

\section{Unmasking of mGluR5-dependent LTP is transient}

Following prolonged deprivation, sensory experience can have both transient (Quinlan et al., 1999a; Philpot et al., 2003; Clem et represent LE+APV).

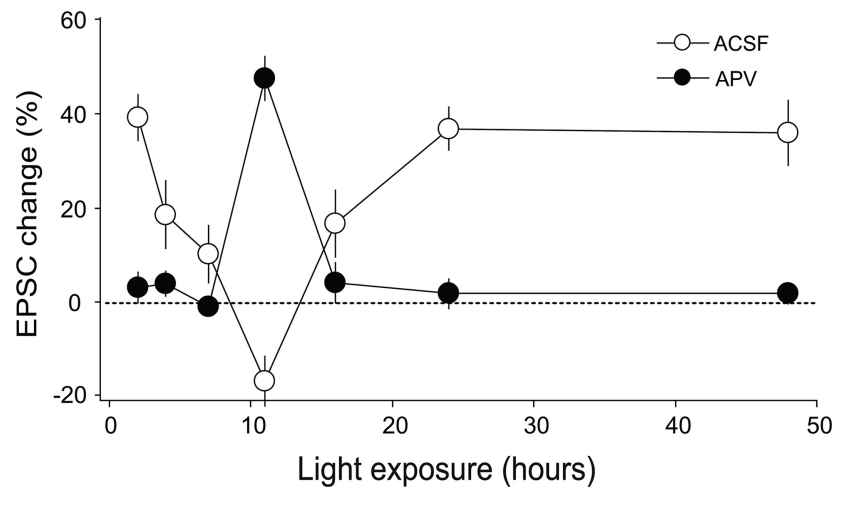

Figure 5. mGluR5-dependent LTP is transient. Developmental changes in the magnitude of LTP in layer 2/3 during LE recorded in ACSF (open circles) and in the presence of APV (filled circles).
A Juvenile mice

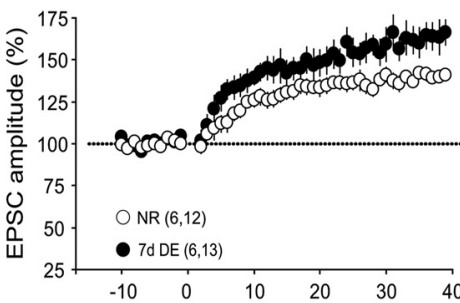

C Young mice

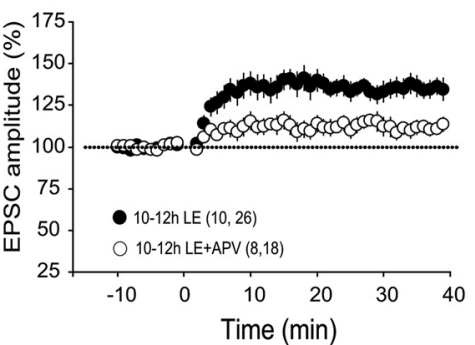

B Adult mice

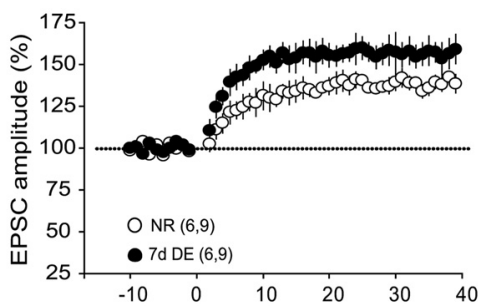

D Adult mice

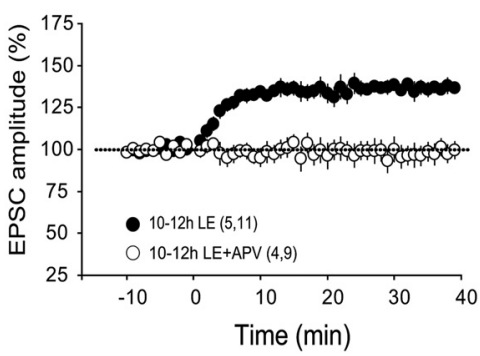

Figure 6. Prior visual experience prevents the unmasking of mGluR5-LTP in both juvenile and adult mice. A, DE (from P21 to 27) elicited much more robust LTP in juvenile mice (filled circles represent DE; open circles represent NR). $\boldsymbol{B}, \mathrm{DE}$ (from P46 to P52) to elicit mGluR5-dependent LTP in juvenile and adult mice after $7 \mathrm{~d}$ DE, respectively (filled circles represent LE; open circles

al., 2008) and permanent (Morales et al., 2002; Jiang et al., 2010a, b) consequences for synaptic function. To address whether the capacity to induce of mGluR-LTP unmasked by vision is transient or long-lasting, we evaluated the magnitude of mGluR5-LTP in slices from dark-reared mice subjected to different durations of LE. The experiments were done in the presence and absence of APV. As shown in Figure 5, the unmasking of mGluR-LTP is delayed and transient, occurring between the 6th and the 16th hour of exposure, peaking at approximately the 12th hour (Kruskal-Wallis test followed by Dunn's comparison test, $p<$ 0.0001). This spike in the expression of mGluR5-LTP mirrored a transient loss of NMDAR-dependent LTP (Kruskal-Wallis test followed by Dunn's comparison test, $p<0.0001$ ). In sum, these results suggested that the unmasking of an mGluR5-LTP is transient, lasting $<10 \mathrm{~h}$, and it delayed by at least $6 \mathrm{~h}$ from the onset of vision. 


\section{Prior visual experience prevents the unmasking of mGluR5-LTP both in juvenile and adult mice}

Another form of visual deprivation, DE after normal rearing also induces detectable change in synaptic transmission (Quinlan et al., 1999a; Philpot et al., 2001; Goel et al., 2006; Goel and Lee, 2007) and plasticity (Guo et al., 2012). We examined whether reexposure to light after DE enables the induction of mGluR5LTP in juvenile and adult NR mice. In the experiments, mice were exposed to dark for $7 \mathrm{~d}$ starting at either P21 (juvenile) or P45 (adult); a subset of mice were then reexposed to light for 10-12 h. As shown in Fig. 6A, juvenile mice exposed to dark exhibited a larger LTP than their age-matched normal reared control NR mice (DE: $158.8 \pm 6.1 \%, n=13$ cells, 6 mice; NR: $137.6 \pm 2.8 \%$, $n=12$ cells, 6 mice; unpaired $t$ test, $\left.t_{(23)}=3.09, p=0.0052\right)$. However, in contrast to the case of DR mice, in DE mice, the reexposure to light did not promote LTD. After LE, the LTP magnitude was normal and it was substantially reduced by APV (10-12 h LE: $134.3 \pm 4.2 \%, n=26$ cells, 10 mice; APV: $112.8 \pm$ $3.8 \%, n=18$ cells, 8 mice; unpaired $t$ test, $t_{(42)}=3.645, p=$ 0.0007; Fig. 6C). Similar results were observed in adult mice. DE increased LTP (DE: $155.3 \pm 6.2 \% ; n=9$ cells, 6 mice; NR: $137.5 \pm 2.9 \%, n=9$ cells, 6 mice; unpaired $t$ test, $t_{(16)}=2.992$, $p=0.0086$; Fig. $6 B$ ), and reexposure to light restored the normal LTP magnitude without revealing mGluR5-LTP (10-12 h LE: $136.7 \pm 2.9 \%, n=11$ cells, 5 mice; APV: $97.6 \pm 5.1 \%, n=9$ cells, 4 mice; unpaired $t$ test, $t_{(18)}=6.935, p<0.0001$; Fig. $\left.6 D\right)$. These data suggested that DE, like DR, enhances NMDAR-LTP, but unlike DR, it does not allow substantial mGluR5-LTP upon reexposure to light. Collectively, these results indicated that prior visual experience reduces mGluR5-LTP in both juvenile and adult mice.

\section{Discussion}

Our examination of the effects of LE after DR revealed a novel NMDAR-independent form of LTP in the layer 2/3 pyramidal cells of mouse visual cortex. This type of LTP depends on mGluR5, intracellular $\mathrm{Ca}^{2+}$, PKC and CaMKII activities, and intact protein synthesis. The expression of mGluR-dependent LTP is transient and can be induced only when mice reared in the dark from birth are exposed to light for 10-12 h, and it was not induced in vision-experienced mice after prolonged exposure to dark. Thus, the mGluR5-LTP unmasked by short visual experience can only be observed after DR but not after DE.

Metabotropic glutamate receptor(s)-mediated plasticity is best understood in CA1 synapses of the hippocampus where both mGluR-LTD (Lüscher and Huber, 2010) and mGluR-LTP (Wang et al., 2016), as well as a role of mGluRs in NMDAR-LTP (Bortolotto et al., 1994), have been demonstrated. Common features shared by mGluR-LTP described here and in CA1 are role of mGluR, normal protein translation (Wang et al., 2016), and intracellular $\mathrm{Ca}^{2+}$ (Grover and Teyler, 1990). However, in CA1, the direct application of the metabotropic agonist DHPG induces LTD (Lüscher and Huber, 2010), rather than LTP, as it does in the LE visual cortex.

Previous studies have reported mGluR-LTP in visual cortical slices. In NR animals, and under standard recording conditions, mGluR-dependent LTP is detectable in infragranular layers only, not in supragranular layers, where synaptic plasticity is supported primarily by NMDAR-dependent mechanisms (Daw et al., 2004). An mGluR5-dependent form of LTP can be demonstrated in layer $2 / 3$, but under partial pharmacological disinhibition and with conditioning subthreshold for inducing NMDAR-LTP (Huemmeke et al., 2002). In this regard, it is interesting to note that, during exposure to light, the transient unmasking of mGluR-LTP coincides with a transient reduction of NMDAR-LTP. These observations, along the laminar and nonoverlapping segregation of NMDAR- and mGluR-dependent LTP, suggest that visual cortical synapses might support both mechanisms of LTP, but not simultaneously. A "pull-push" type of coregulation of plasticity mechanisms is also observed in other synapses. In the aging hippocampus, some individuals counterbalance the decline in NMDAR-dependent plasticity by upregulating mGluR-dependent synaptic plasticity (Lee et al., 2005; Boric et al., 2008; Yang et al., 2013). Similarly, a mutual inhibition of mGluR-LTD and NMDAR-LTD has been suggested to occur in some inputs to the basal amygdala (Clem and Huganir, 2013). Thus, the mutual inhibition of mGluR- and NMDAR-dependent plasticity is seemingly a widespread feature among central synapses, although synergy has also been reported (Bortolotto et al., 1994). The underlying mechanisms of these interactions remain unknown, although they might serve an adaptive function. For example, under certain regimens of neural activity, mGluR-LTP might be more effective than NMDAR-LTP in inducing synaptic changes.

The functional consequences of the transient enhancement of mGluR-LTP during the first exposure to light in deprived mice are currently unclear. Notably, in the inexperienced barrel cortex, a similar transient mGluR-LTP is also observed after whisker stimulation (Clem et al., 2008; Wen et al., 2013). In a similar fashion, light after prolonged DE results in a transient "rebound potentiation" of the postsynaptic strength of inhibitory transmission in adult mice (Gao et al., 2014). These transiently expressed potentiation mechanisms might allow a fast reorganization of deprived cortices. Individuals reared in complete darkness respond slowly to light and lack the stimulus selectivity that is characteristic of NR animals (Borges and Berry, 1978; Fagiolini et al., 1994). In juvenile individuals, the effects of DR can be rapidly reversed within few hours of LE (Quinlan, 1999b). Similarly, during the critical period, the recovery of normal cortical function is faster than deprivation-induced changes (Krahe et al., 2005). These observations suggest that the sudden exposure sensory drive in deprived cortex recruits the dormant mechanisms of plasticity, like mGluR5-LTP, which allows a faster establishment of normal receptive field properties.

\section{References}

Abraham WC, Bear MF (1996) Metaplasticity: the plasticity of synaptic plasticity. Trends Neurosci 19:126-130. CrossRef Medline

Artola A, Singer W (1987) Long-term potentiation and NMDA receptors in rat visual cortex. Nature 330:649-652. CrossRef Medline

Bear MF (2003) Bidirectional synaptic plasticity: from theory to reality. Philos Trans R Soc Lond B Biol Sci 358:649-655. CrossRef Medline

Bear MF, Press WA, Connors BW (1992) Long-term potentiation in slices of kitten visual cortex and the effects of NMDA receptor blockade. J Neurophysiol 67:841-851. Medline

Borges S, Berry M (1978) The effects of dark rearing on the development of the visual cortex of the rat. J Comp Neurol 180:277-300. CrossRef Medline

Boric K, Muñoz P, Gallagher M, Kirkwood A (2008) Potential adaptive function for altered long-term potentiation mechanisms in aging hippocampus. J Neurosci 28:8034-8039. CrossRef Medline

Bortolotto ZA, Bashir ZI, Davies CH, Collingridge GL (1994) A molecular switch activated by metabotropic glutamate receptors regulates induction of long-term potentiation. Nature 368:740-743. CrossRef Medline

Capogna M (2004) Distinct properties of presynaptic group II and III metabotropic glutamate receptor-mediated inhibition of perforant pathway-CA1 EPSCs. Eur J Neurosci 19:2847-2858. CrossRef Medline

Clem RL, Huganir RL (2013) Norepinephrine enhances a discrete form of long-term depression during fear memory storage. J Neurosci 33:1182511832. CrossRef Medline 
Clem RL, Celikel T, Barth AL (2008) Ongoing in vivo experience triggers synaptic metaplasticity in the neocortex. Science 319:101-104. CrossRef Medline

Cooke SF, Bear MF (2010) Visual experience induces long-term potentiation in the primary visual cortex. J Neurosci 30:16304-16313. CrossRef Medline

D’Angelo E, Rossi P, Armano S, Taglietti V (1999) Evidence for NMDA and mGlu receptor-dependent long-term potentiation of mossy fiber-granule cell transmission in rat cerebellum. J Neurophysiol 81:277-287. Medline

Daw N, Rao Y, Wang XF, Fischer Q, Yang Y (2004) LTP and LTD vary with layer in rodent visual cortex. Vision Res 44:3377-3380. CrossRef Medline

Fagiolini M, Pizzorusso T, Berardi N, Domenici L, Maffei L (1994) Functional postnatal development of the rat primary visual cortex and the role of visual experience: dark rearing and monocular deprivation. Vision Res 34:709-720. CrossRef Medline

Gao M, Maynard KR, Chokshi V, Song L, Jacobs C, Wang H, Tran T, Martinowich K, Lee HK (2014) Rebound potentiation of inhibition in juvenile visual cortex requires vision-induced BDNF expression. J Neurosci 34:10770-10779. CrossRef Medline

Goel A, Lee HK (2007) Persistence of experience-induced homeostatic synaptic plasticity through adulthood in superficial layers of mouse visual cortex. J Neurosci 27:6692-6700. CrossRef Medline

Goel A, Jiang B, Xu LW, Song L, Kirkwood A, Lee HK (2006) Cross-modal regulation of synaptic AMPA receptors in primary sensory cortices by visual experience. Nat Neurosci 9:1001-1003. CrossRef Medline

Grover LM, Teyler TJ (1990) Two components of long-term potentiation induced by different patterns of afferent activation. Nature 347:477-479. CrossRef Medline

Guo Y, Huang S, de Pasquale R, McGehrin K, Lee HK, Zhao K, Kirkwood A (2012) Dark exposure extends the integration window for spike-timingdependent plasticity. J Neurosci 32:15027-15035. CrossRef Medline

Hardingham N, Wright N, Dachtler J, Fox K (2008) Sensory deprivation unmasks a PKA-dependent synaptic plasticity mechanism that operates in parallel with CaMKII. Neuron 60:861-874. CrossRef Medline

Heynen AJ, Bear MF (2001) Long-term potentiation of thalamocortical transmission in the adult visual cortex in vivo. J Neurosci 21:9801-9813. Medline

Huber KM, Kayser MS, Bear MF (2000) Role for rapid dendritic protein synthesis in hippocampal mGluR-dependent long-term depression. Science 288:1254-1257. CrossRef Medline

Huemmeke M, Eysel UT, Mittmann T (2002) Metabotropic glutamate receptors mediate expression of LTP in slices of rat visual cortex. Eur J Neurosci 15:1641-1645. CrossRef Medline

Jiang B, Treviño M, Kirkwood A (2007) Sequential development of longterm potentiation and depression in different layers of the mouse visual cortex. J Neurosci 27:9648-9652. CrossRef Medline

Jiang B, Huang S, de Pasquale R, Millman D, Song L, Lee HK, Tsumoto T, Kirkwood A (2010a) The maturation of GABAergic transmission in visual cortex requires endocannabinoid-mediated LTD of inhibitory inputs during a critical period. Neuron 66:248-259. CrossRef Medline

Jiang B, Sohya K, Sarihi A, Yanagawa Y, Tsumoto T (2010b) Laminarspecific maturation of GABAergic transmission and susceptibility to visual deprivation are related to endocannabinoid sensitivity in mouse visual cortex. J Neurosci 30:14261-14272. CrossRef Medline

Kimura F, Nishigori A, Shirokawa T, Tsumoto T (1989) Long-term potentiation and $\mathrm{N}$-methyl-D-aspartate receptors in the visual cortex of young rats. J Physiol 414:125-1144. CrossRef Medline

Kingston AE, Ornstein PL, Wright RA, Johnson BG, Mayne NG, Burnett JP, Belagaje R, Wu S, Schoepp DD (1998) LY341495 is a nanomolar potent and selective antagonist of group II metabotropic glutamate receptors. Neuropharmacology 37:1-12. CrossRef Medline

Kirkwood A, Bear MF (1994) Hebbian synapses in visual cortex. J Neurosci 14:1634-1645. Medline

Kirkwood A, Lee HK, Bear MF (1995) Co-regulation of long-term potentiation and experience-dependent synaptic plasticity in visual cortex by age and experience. Nature 375:328-331. CrossRef Medline

Kirkwood A, Rioult MC, Bear MF (1996) Experience-dependent modification of synaptic plasticity in visual cortex. Nature 381:526-528. CrossRef Medline

Komatsu Y, Toyama K, Maeda J, Sakaguchi H (1981) Long-term potentiation investigated in a slice preparation of striate cortex of young kittens. Neurosci Lett 26:269-274. CrossRef Medline
Krahe TE, Medina AE, de Bittencourt-Navarrete RE, Colello RJ, Ramoa AS (2005) Protein synthesis-independent plasticity mediates rapid and precise recovery of deprived eye responses. Neuron 48:329-343. CrossRef Medline

Lee HK, Min SS, Gallagher M, Kirkwood A (2005) NMDA receptorindependent long-term depression correlates with successful aging in rats. Nat Neurosci 8:1657-1659. CrossRef Medline

Lisman J, Schulman H, Cline H (2002) The molecular basis of CaMKII function in synaptic and behavioural memory. Nat Rev Neurosci 3:175190. CrossRef Medline

Lüscher C, Huber KM (2010) Group 1 mGluR-dependent synaptic longterm depression: mechanisms and implications for circuitry and disease. Neuron 65:445-459. CrossRef Medline

Morales B, Choi SY, Kirkwood A (2002) Dark rearing alters the development of GABAergic transmission in visual cortex. J Neurosci 22:80848090. Medline

Nicoll RA, Malenka RC (1999) Expression mechanisms underlying NMDA receptor-dependent long-term potentiation. Ann N Y Acad Sci 868:515525. CrossRef Medline

Palmer MJ, Irving AJ, Seabrook GR, Jane DE, Collingridge GL (1997) The group I mGlu receptor agonist DHPG induces a novel form of LTD in the CA1 region of the hippocampus. Neuropharmacology 36:1517-1532. CrossRef Medline

Philpot BD, Sekhar AK, Shouval HZ, Bear MF (2001) Visual experience and deprivation bidirectionally modify the composition and function of NMDA receptors in visual cortex. Neuron 29:157-169. CrossRef Medline

Philpot BD, Espinosa JS, Bear MF (2003) Evidence for altered NMDA receptor function as a basis for metaplasticity in visual cortex. J Neurosci 23:5583-5588. Medline

Quinlan EM, Olstein DH, Bear MF (1999a) Bidirectional, experiencedependent regulation of $\mathrm{N}$-methyl-D-aspartate receptor subunit composition in the rat visual cortex during postnatal development. Proc Natl Acad Sci U S A 96:12876-12880. CrossRef Medline

Quinlan EM, Philpot BD, Huganir RL, Bear MF (1999b) Rapid, experiencedependent expression of synaptic NMDA receptors in visual cortex in vivo. Nat Neurosci 2:352-357. CrossRef Medline

Rao Y, Daw NW (2004) Layer variations of long-term depression in rat visual cortex. J Neurophysiol 92:2652-2658. CrossRef Medline

Rumbaugh G, Vicini S (1999) Distinct synaptic and extrasynaptic NMDA receptors in developing cerebellar granule neurons. J Neurosci 19:1060310610. Medline

Scott HL, Braud S, Bannister NJ, Isaac JT (2007) Synaptic strength at the thalamocortical input to layer IV neonatal barrel cortex is regulated by protein kinase C. Neuropharmacology 52:185-192. CrossRef Medline

Sun W, Wang L, Li S, Tie X, Jiang B (2015) Layer-specific endocannabinoidmediated long-term depression of GABAergic neurotransmission onto principal neurons in mouse visual cortex. Eur J Neurosci 42:1952-1965. CrossRef Medline

Tsumoto T (1992) Long-term potentiation and long-term depression in the neocortex. Prog Neurobiol 39:209-228. CrossRef Medline

Wang H, Ardiles AO, Yang S, Tran T, Posada-Duque R, Valdivia G, Baek M, Chuang YA, Palacios AG, Gallagher M, Worley P, Kirkwood A (2016) Metabotropic glutamate receptors induce a form of LTP controlled by translation and arc signaling in the hippocampus. J Neurosci 36:17231729. CrossRef Medline

Wang XF, Daw NW (2003) Long term potentiation varies with layer in rat visual cortex. Brain Res 989:26-34. CrossRef Medline

Wen JA, DeBlois MC, Barth AL (2013) Initiation, labile, and stabilization phases of experience-dependent plasticity at neocortical synapses. J Neurosci 33:8483-8493. CrossRef Medline

Yamada K, Inagaki T, Funahashi R, Yoshimura Y, Komatsu Y (2006) Highfrequency stimulation together with adrenoceptor activation facilitates the maintenance of long-term potentiation at visual cortical inhibitory synapses. Cereb Cortex 16:1239-1248. CrossRef Medline

Yang S, Megill A, Ardiles AO, Ransom S, Tran T, Koh MT, Lee HK, Gallagher M, Kirkwood A (2013) Integrity of mGluR-LTD in the associative/commissural inputs to CA3 correlates with successful aging in rats. J Neurosci 33:12670-12678. CrossRef Medline

Yasuda H, Barth AL, Stellwagen D, Malenka RC (2003) A developmental switch in the signaling cascades for LTP induction. Nat Neurosci 6:15-16. CrossRef Medline 